\title{
Changes in Regional Potential Vegetation in Response to an Ambitious Mitigation Scenario
}

\author{
Heike Huebener ${ }^{1}$, Janina Körper ${ }^{2}$ \\ ${ }^{1}$ Hessian Agency for Environment and Geology, Wiesbaden, Germany; ${ }^{2}$ Freie Universität Berlin, Institut für Meteorolgie, Berlin, \\ Germany. \\ Email: heike.huebener@hlug.hessen.de
}

Received May $25^{\text {th }}, 2013$; revised June $3^{\text {rd }}, 2013$; accepted July $26^{\text {th }}, 2013$

Copyright (C) 2013 Heike Huebener, Janina Körper. This is an open access article distributed under the Creative Commons Attribution License, which permits unrestricted use, distribution, and reproduction in any medium, provided the original work is properly cited.

\begin{abstract}
Climate change impacts on the potential vegetation (biomes) are compared for an ambitious emissions-reduction scenario (E1) and a medium-high emissions scenario with no mitigation policy (A1B). The E1 scenario aims at limiting global mean warming to $2^{\circ} \mathrm{C}$ or less above pre-industrial temperatures and is closely related to the RCP2.6 sued in the CMIP5. A multi-model ensemble of ten state-of-the-art coupled atmosphere-ocean general circulation models (GCMs) is analyzed. A simple biome model is used to assess the response of potential vegetation to the different forcing in the two scenarios. Changes in biomes in response to the simulated climate change are less pronounced in E1 than in the A1B scenario. Most biomes shift polewards, with biomes adapted to colder climates being replaced by biomes adapted to warmer climates. In some regions cold biomes (e.g. Tundra, Taiga) nearly disappear in the A1B scenario but are also significantly reduced under the E1 scenario.
\end{abstract}

Keywords: Climate Change; Mitigation Scenario; Potential Vegetation

\section{Introduction}

The new socio-economic scenarios used in the fifth assessment report of the Intergovernmental Panel on Climate Change (IPCC), the "Representative Concentration Pathway" (RCP)-Scenarios [1] now include explicit mitigation policies. Thus, for the preparation of adaptation actions, an assessment of anticipated changes under strong mitigation scenarios compared to scenarios without mitigation is necessary.

In the EU-funded project ENSEMBLES [2] a mitigation scenario was developed that aims at keeping the $2^{\circ}$-target: the E1 scenario [3]. E1 starts from an emission path corresponding to the "Special Report on Emission Scenarios" (SRES) A1B scenario, projecting greenhouse gas (GHG) concentrations to stabilize at $450 \mathrm{ppmv} \mathrm{CO}_{2}$ equivalent $\left(\mathrm{CO}_{2}\right.$-e $)$ in the $22^{\text {nd }}$ century after an overshoot to 530 ppmv in the mid $21^{\text {st }}$ century $([3,4])$.

Current aerosol trends indicate that the increasing aerosol levels in the SRES A1B scenario are overestimated (e.g. [5,6]). The E1 scenario generates a lower aerosol loading than A1B. This leads to a stronger temperature increase in the E1 scenario compared to the SRES A1B scenario in the first half of the $21^{\text {st }}$ century, despite the reduced greenhouse gas forcing. [4] highlights a non-linear precipitation versus temperature response in some models, possibly related to the balance of surface net radiation induced by the aerosol forcing. Thus, the global mean precipitation increase per degree warming is stronger in the E1 scenario than in the A1B scenario. This effect was already noted in the comparison between the A1B and the "Commit" experiment of the CMIP3 simulations [7] but it is even stronger in E1 compared with A1B [4]. [8] underscores the stronger precipitation response per degree warming in the regional analyses in the E1 scenario compared to the A1B scenario.

Simulations using the A1B and E1 scenarios are analyzed. Model descriptions for the contributing coupled atmosphere-ocean general circulation models (GCMs) and global mean results for temperature, precipitation and carbon cycle fluxes are given in [4]. An analysis of regional precipitation, cloud cover and evapotranspiration is given in [8]. Sea ice and sea level changes are assessed in [9].

The terrestrial biosphere is especially vulnerable to climatic changes [10]. Since anthropogenic land-use change is expected to have the largest effect [11] it is explicitly used as an anthropogenic driver in both of the scenarios 
analyzed here. Continental scale shifts of biomes, i.e. major regional ecosystems consisting of typical plants, are projected for a future climate in response to regional temperature and water availability changes (e.g. [10,12, 13]). Since biomes depend on distinct hydrological and thermal thresholds, their response to climate change is not a simple linear shift in response to changes in temperature and/or precipitation. Moreover, there are biomes that are more sensitive to temperature changes and other biomes that respond to hydrological changes such as water stress $([11,14])$. By analyzing biome shifts simulated in the E1 and the SRES A1B scenarios, we examine whether exceeding these specific thresholds may be avoided by aggressive mitigation measures. Here, we use offline biome calculations to analyze the complete set of available simulations.

We focus on the changes in biomes derived from the climatological monthly means of temperature, precipitation and cloud cover employing the BIOME1 model [15]. The models, data, and methods are described in Section 2. Biome results for the 26 Giorgi-regions form Section 3. In Section 4 the results are summarized and discussed.

\section{Data and Methods}

The models contributing to this study are given in Table 1 (see [4] for further details). Simulations for the historical time period 1860-2100 use observed GHG-forcings until the year 2000 (i.e. most simulations exclude solar and volcanic variations) and two future scenarios for the time period 2001-2100: The SRES A1B scenario, which does not include an explicit climate mitigation policy and the mitigation scenario E1 which aims at keeping the $2^{\circ}$ target.

For some, but not all, of the contributing models several simulations were performed, using different initial conditions. In these cases, the simulation results were averaged over all simulations, thus weighting each model equally in the multi-model ensemble analysis.

In accordance with previous analyses (e.g. $[8,16,17])$ we use the so-called "Giorgi-regions" [18] and consider changes over land areas only. Figure 1 shows the Giorgiregions and Table 2 gives the abbreviations used in the

Table 1. Contributing models, research institutes and references.

\begin{tabular}{|c|c|c|}
\hline Model name & Institution & Ref. \\
\hline HadGEM2-AO & Met-Office, UK & $\begin{array}{l}\text { Johns et al. (2006), } \\
\text { Collins et al. (2008) }\end{array}$ \\
\hline HadCM3C & Met-Office, UK & $\begin{array}{l}\text { Gordon et al. }(2000) \\
\text { Pope et al. }(2000) ; \\
\text { Cox et al. }(2000)\end{array}$ \\
\hline IPSL-CM4 & IPSL, France & Marti et al. (2010) \\
\hline IPSL-CM4-LOOP & IPSL, France & Cadule et al. (2009) \\
\hline ECHAM5-C & MPI-M, Germany & $\begin{array}{l}\text { Roeckner et al. (2006); } \\
\text { Marsland et al. (2003) }\end{array}$ \\
\hline EGMAM+ & FUB, Germany & Huebener et al. (2007) \\
\hline INGVCE & CMCC, Italy & $\begin{array}{l}\text { Fogli et al. (2009); } \\
\text { Vichi et al. (2011) }\end{array}$ \\
\hline CNRM-CM3.3 & CNRM, France & Salas-Mélia et al. (2005) \\
\hline BCM2 & BCCR, Norway & Furevik et al. (2003) \\
\hline $\mathrm{BCM}-\mathrm{C}$ & BCCR, Norway & Tjiputra et al. (2010) \\
\hline
\end{tabular}

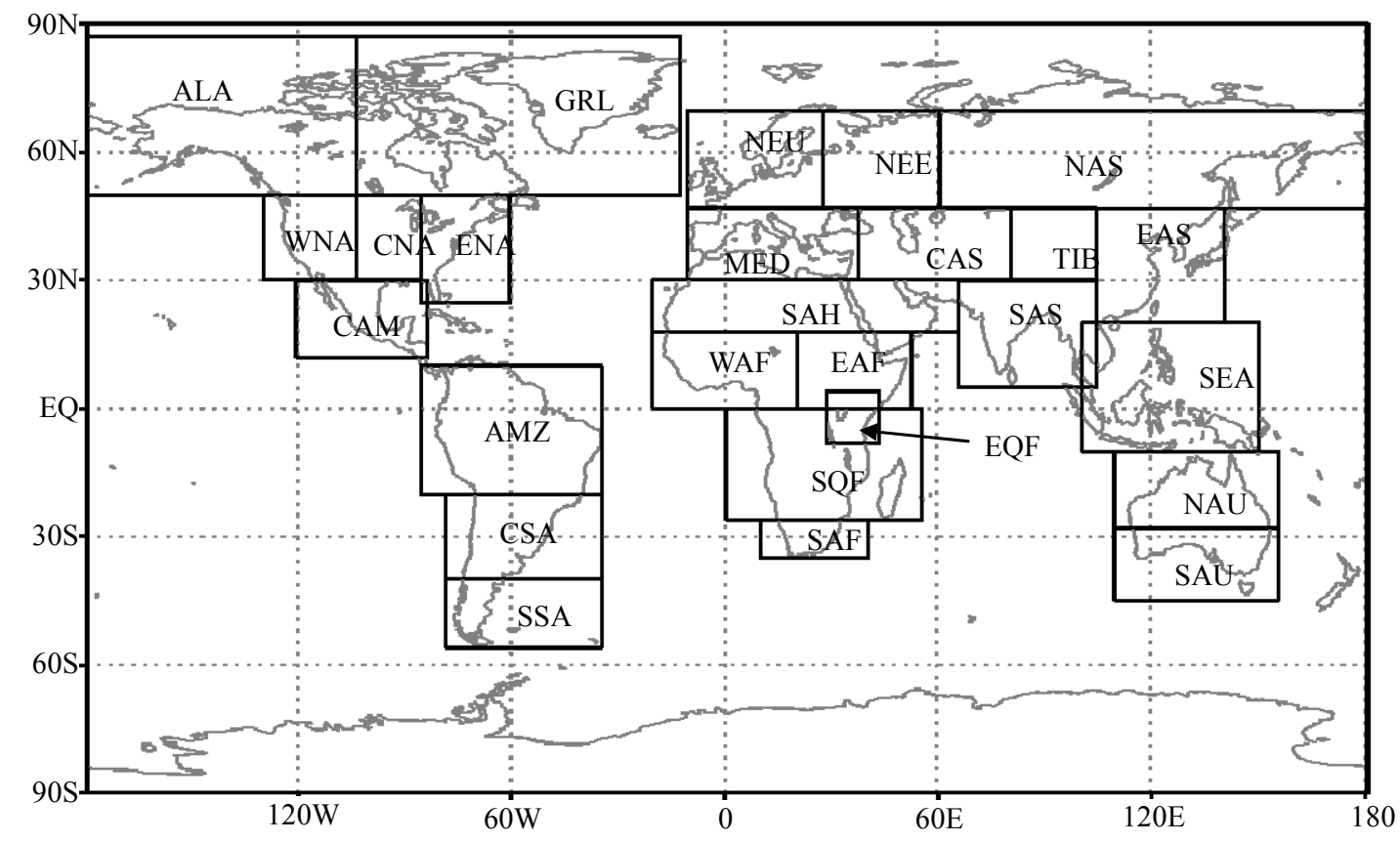

Figure 1. Giorgi-regions: outlines and abbreviations. 
Table 2. Giorgi-regions: Abbreviations, region names and geographic borders.

\begin{tabular}{|c|c|c|c|c|c|}
\hline Region abbreviation & Region name & West & East & South & North \\
\hline NEU & Northern Europe & -10.5 & 27.5 & 47.0 & 70.0 \\
\hline MED & Mediterranean Basin & -10.5 & 37.5 & 30.0 & 47.0 \\
\hline NEE & North-Eastern Europe & 27.5 & 60.5 & 47.0 & 70.0 \\
\hline NAS & North Asia & 60.5 & 180.5 & 47.0 & 70.0 \\
\hline CAS & Central Asia & 37.5 & 80.5 & 30.0 & 47.0 \\
\hline TIB & Tibet & 80.5 & 104.5 & 30.0 & 47.0 \\
\hline EAS & East Asia & 104.5 & 140.5 & 20.0 & 47.0 \\
\hline SAS & South Asia & 65.5 & 104.5 & 5.0 & 30.0 \\
\hline SEA & Southeast Asia & 100.5 & 150.5 & -10.0 & 20.0 \\
\hline NAU & North Australia & 109.5 & 155.5 & -28.0 & -10.0 \\
\hline SAU & South Australia & 109.5 & 155.5 & -45.0 & -28.0 \\
\hline SAH & Sahara & -20.5 & 65.5 & 18.0 & 30.0 \\
\hline WAF & Western Africa & -20.5 & 20.5 & 0.0 & 18.0 \\
\hline EAF & Eastern Africa & 20.5 & 52.5 & 0.0 & 18.0 \\
\hline $\mathrm{EQF}$ & Equatorial Africa & 28.5 & 43.5 & -8.0 & 4.0 \\
\hline SQF & Southern Equatorial Africa & 0.5 & 55.5 & -26.0 & 0.0 \\
\hline SAF & Southern Africa & 10.0 & 40.5 & -35.0 & -26.0 \\
\hline ALA & Alaska & -179.5 & -103.5 & 50.0 & 87.0 \\
\hline GRL & Greenland & -103.5 & -12.5 & 50.0 & 87.0 \\
\hline WNA & Western North America & -129.5 & -103.5 & 30.0 & 50.0 \\
\hline CNA & Central North America & -103.5 & -85.5 & 30.0 & 50.0 \\
\hline ENA & Eastern North America & -85.5 & -60.5 & 25.0 & 50.0 \\
\hline CAM & Central America & -120.5 & -83.5 & 12.0 & 30.0 \\
\hline $\mathrm{AMZ}$ & Amazon Basin & -85.5 & -34.5 & -20.0 & 10.0 \\
\hline CSA & Central South America & -78.5 & -34.5 & -40.0 & -20.0 \\
\hline SSA & Southern South America & -78.5 & -34.5 & -56.0 & -40.0 \\
\hline
\end{tabular}

following of this paper, the region full names and the geographic borders. We analyze the changes in the biomes distributions between the two periods 2080-2099 and 1980-1999, as used in [4].

For the analysis of the biomes, all model data were interpolated onto a common $2.5^{\circ} \times 2.5^{\circ}$ latitude-longitudegrid for further analysis. We focus on the monthly mean changes over two 20 year periods (1980-1999 and 20802099 ) in temperature, precipitation and cloud cover as simulated by the models and the resulting impact on biome distributions. Interannual variability, even though important, is not analysed here.

Biomes current distributions and their projected changes are calculated using the BIOME1 model [15].
While newer versions of the model such as BIOME4 [19] include more than 25 biomes, we use BIOME1 with 17 biomes to assess the most prominent wide-spread changes. Using a limited number of biomes has the advantage of restricting the analyses to the most prominent biomes and avoiding an overinterpretation of the results in the light of the bandwidth of the simulated climate changes, particularly for precipitation and cloud cover.

To assess the models performance observed data are used to calculate biomes and the results are compared to the results obtained from the individual models (not shown) and for the ensemble mean for 1980-1999. To derive a biome map from observations, temperature data from the CRUTS2.1 dataset [20], precipitation data of 
the Global Precipitation Climatology Project [21] and the cloud cover data set of the International Satellite Cloud Climatology Project are interpolated to a $2.5^{\circ} \times 2.5^{\circ}$ grid. Additionally, biomes are also calculated from the National Center for Environmental Prediction (NCEP) ReAnalyses to assess the different biome distribution from using different observational data sets. The resulting present-day biome maps are compared to those calculated from the modeled present-day climate data to evaluate the model performance.

To assess the projected changes of the biomes we apply the delta-change method, which has previously been employed for the analysis for projected changes of the Köppen-Trewartha climate classification maps ([22,23]). For this approach the climate signals of temperature, precipitation and cloud cover (2080-2099 minus 1980-1999) from each model are calculated, as well as the ensemble mean signals. To derive the 2080-2099 biome maps, the change from each model is added to the observed 19801999 climatology. The delta-change method may produce negative precipitation or a cloud cover greater than $100 \%$. These cases that make no physical sense are excluded.

\section{Regional Change in Biomes}

Biomes, or potential vegetation, do not necessarily represent the existing vegetation, particularly in regions where natural vegetation has been replaced by crops. Furthermore, changes in potential vegetation do not include direct anthropogenic disturbance (i.e. deforestation for cropland or pasture). In regions EAS and CNA, more than half of the area is used for crops and pasture. This fraction is between $33 \%$ and $50 \%$ in the regions NEU, NEE, SAS, SAF, CAM, and CSA, while in TIB, NAU, EAF and ALA the respective fraction is $<10 \%$, and in SAH and GRL $<5 \%$ (percentages taken from the cropland and pasture fraction per grid cell land-use data in ENSEMBLES project, cf. [4]). However, for some natural ecosystems, such as large parts of the African rainforests or the Siberian tundra, potential vegetation is a reasonable approximation of current actual vegetation. Additionally, changes in climate might make some regions unsuitable for current land use, even under anthropogenic cultivation. This section aims to provide an insight into natural vegetation dynamics as driven by climate change, but will also briefly address the fraction of land used as either crop land or pasture versus natural vegetation.

To evaluate the agreement between the biome maps generated using observed and modelled climate data, we use kappa statistics [24] including their subjective scale for agreement from "No" to "Perfect" (Table 3). Since the degree of freedom varies for the different regions
Table 3. Scale for spatial agreement based on kappa statistics.

\begin{tabular}{llll}
\hline Kappa values & $\begin{array}{l}\text { Degree of } \\
\text { Agreement }\end{array}$ & Kappa values & $\begin{array}{l}\text { Degree of } \\
\text { agreement }\end{array}$ \\
\hline$<0.05$ & No & $0.55-0.70$ & Good \\
$0.05-0.20$ & Very poor & $0.70-0.85$ & Very good \\
$0.20-0.40$ & Poor & $0.85-0.99$ & Excellent \\
$0.40-0.55$ & Fair & $0.99-1.00$ & Perfect \\
\hline
\end{tabular}

owing to the different numbers of grid boxes per Giorgiregion, kappa values estimate the significance of the difference for a given region only. Therefore, comparing kappa values calculated for regions with different sizes should be avoided. Kappa statistics are also used to assess the difference between the maps for the last two decades of the $21^{\text {st }}$ century and the last two decades of the $20^{\text {th }}$ century for the two scenarios.

Figure 2 shows the calculated biomes for present-day climate for two different observational data-sets and the ensemble mean of the contributing models. The biomes calculated from the ensemble mean simulations shows in most regions biomes in the range of the biomes calculated from the two observational data-sets. In the following we will refer to the biome distribution calculated from CRU and ISCCP data (Figure 2(a)) as "observed" biome patterns.

The main characteristics of the spatial patterns of the present-day biomes are represented well using the ensemble mean climate (Figure 2(c)). The kappa values for the global maps, when compared to the map displayed in Figure 2(a), vary between 0.49 and 0.60 for the different models. The Kappa value is highest for the ensemble mean biome map (0.65). It should be noted that the biome of a grid box generated using the ensemble mean climate data is not necessarily the same as the "mean" biome from the individual models.

In some regions the ensemble mean does not depict the observed patterns. For example, in South America all models tend to simulate savannah instead of tropical rain or tropical seasonal forests. The savannah area is largest in BCM-C and smallest in IPSL-CM4, which instead overestimates the extent of xerophytic woods. The largest extent of tropical forests for AMZ is simulated by HADGEM2-AO (largest extent of tropical rainforest) and INGV-CE (largest extent of tropical seasonal forest). Furthermore, in most models the extension of hot desert in CAS is overestimated combined with an underestimated extent of warm grassland. The largest extent of hot desert is found in ECHAM5C. EGMAM+ and HADGEM2-AO agree best with the observed patterns of hot desert and warm grassland (without figures). Globally averaged the ensemble mean overestimates the dry sub- 


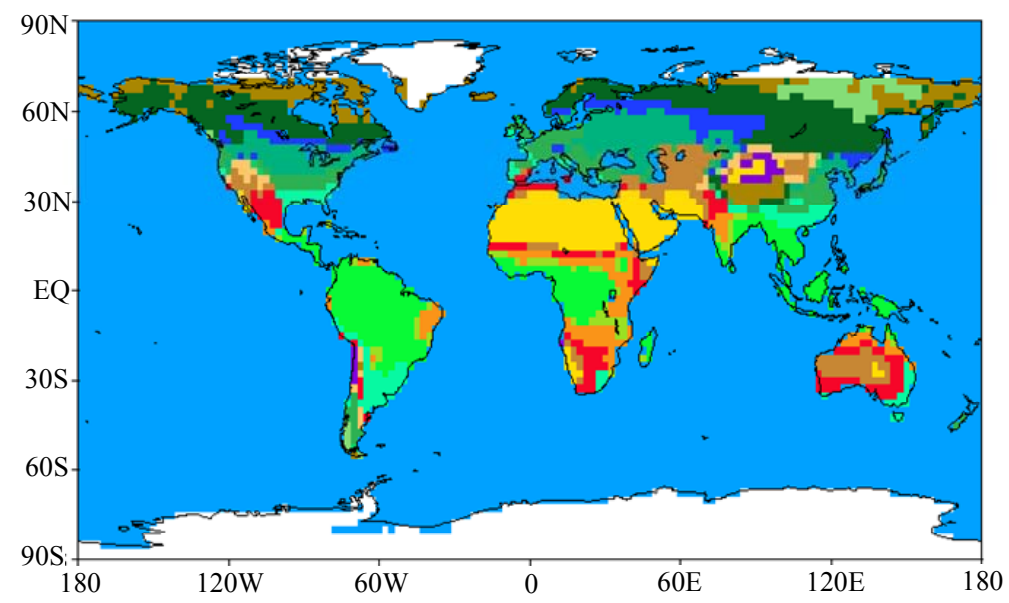

(a)

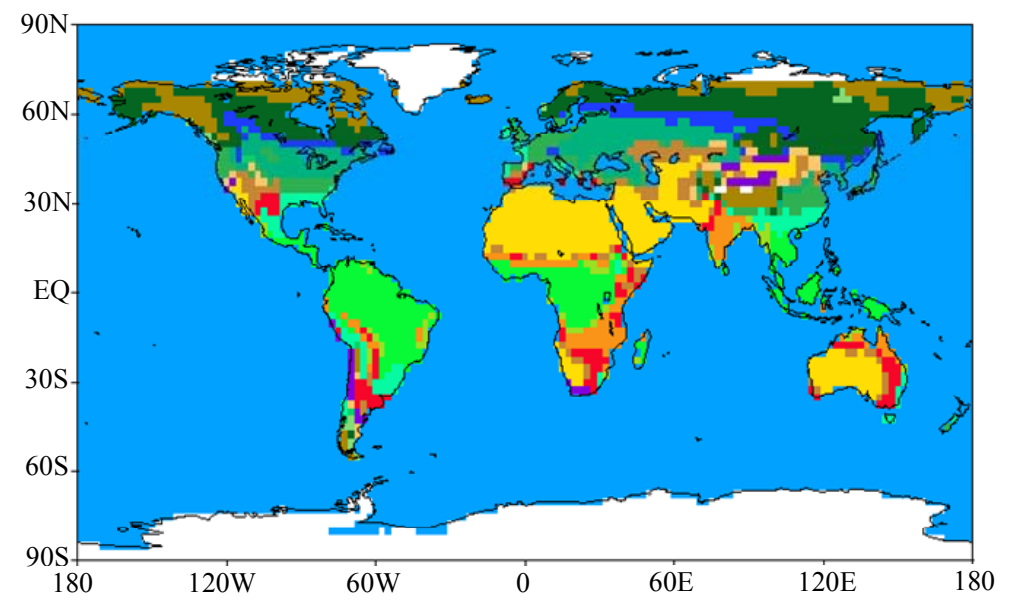

(b)

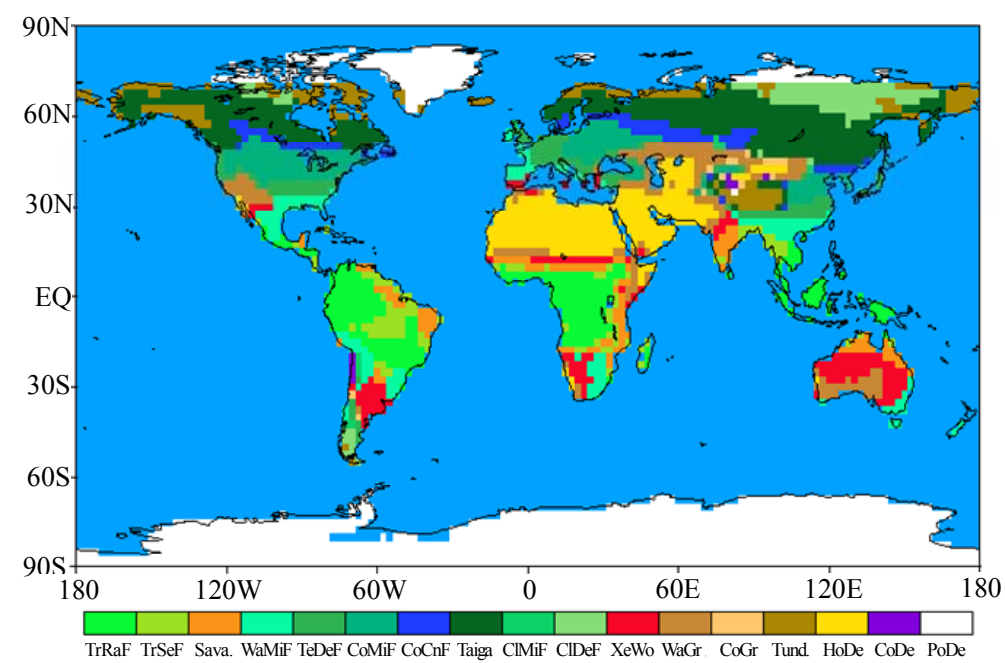

(c)

Figure 2. Calculated biomes using (a) observed 1980-1999 CRU (T), GPCP (P), and ISCCP (cloud cover) data, (b) NCEP Re-Analyses and (c) simulated ensemble mean data for 1980-1999. Biomes abbreviations: TrRaF = Tropical Rain Forest, TrSeF $=$ Tropical Seasonal Forest, Sava $=$ Savannah, WaMiF $=$ Warm Mixed Forest, TeDeF $=$ Temperate Deciduous Forest, CoMiF $=$ Cool Mixed Forest, $\mathrm{CoCnF}=\mathrm{Cool}$ Conifer Forest, Taiga $=$ Taiga, CIMiF $=$ Cold Mixed Forest, CIDeF $=$ Cold Deciduous Forest, XeWo $=$ Xerophytic Woods/Shrub, WaGr $=$ Warm Grass/Shrub, CoGr $=$ Cool Grass/Shrub, Tund. $=$ Tundra, HoDe $=$ Hot Desert, CoDe $=$ Cool Desert, PoDe $=$ Polar Desert $/$ Ice. 
tropical biomes hot desert, xerophytic woods and savannah and underestimates the extent of tropical forests. Largest ensemble spread is evident for hot desert and savannah, but also for taiga and tundra, for which the globally averaged ensemble mean is fairly close to observations (Figure 3).

Owing to the warming in the $21^{\text {st }}$ century in both scenarios we find a poleward shift of the dominating biomes, leading to a retreat of northern hemispheric taiga and tundra in all models. Because of the drying in the subtropical land areas the extent of savannah, warm grassland and hot desert increases (without figures).

The changes in potential vegetation are analysed in detail using 24 Giorgi-regions (Figure 4). The regions SAH and SEA are excluded since the biomes there display only one type (SAH: hot desert, SEA: tropical rain forest) and no significant changes are simulated in either scenario. In the tropical regions consistent with the differences in the precipitation projections the models reveal large differences in biome projections.

In South Asia (SAS) there is a tendency for an increase of savannah replacing forest types. In Southern Equatorial Africa (SQF) and Western Africa (WAF) only small changes are simulated. Note that in these regions anthropogenic land use increases by more than ten per- cent of the area in the E1 scenario prescribed land use. In the Amazonas Basin (AMZ) the extent of tropical rainforests decreases from about $49 \%$ to about $38 \%$ in the SRES A1B scenario and to $44 \%$ in the E1 scenario. However, the differences between the models are large, consistent with the differences in precipitation, cloud cover and evapotranspiration in this region, as shown by [8]. For AMZ simulated biome changes range from very small (Kappa $=0.88$ derived from the CNRM-CM3 model) to quite large (strongest decrease in tropical forest to about $11 \%$ - $16 \%$ of the total land area derived from HADGEM2-AO and HADCM3C). Rainforests are replaced by savannah, as a result of drying in this region.

In the northern hemispheric subtropics biome changes are relatively small (Figure 4). In the Mediterranean Basin (MED) temperate deciduous forests are replaced mainly by warm mixed forest and warm grassland. The latter effect is stronger in the SRES A1B scenario compared to E1 due to the stronger drying in this scenario. In Central America (CAM) the models agree that the dominant present-day biome xerophytic woods is diminished (in E1 significantly less than in A1B), but they disagree on whether it is replaced by warm grassland or savanna. In Central Asia (CAS) the models simulate an expansion of hot desert only in A1B. In the southern hemispheric

Present day biomes for Global

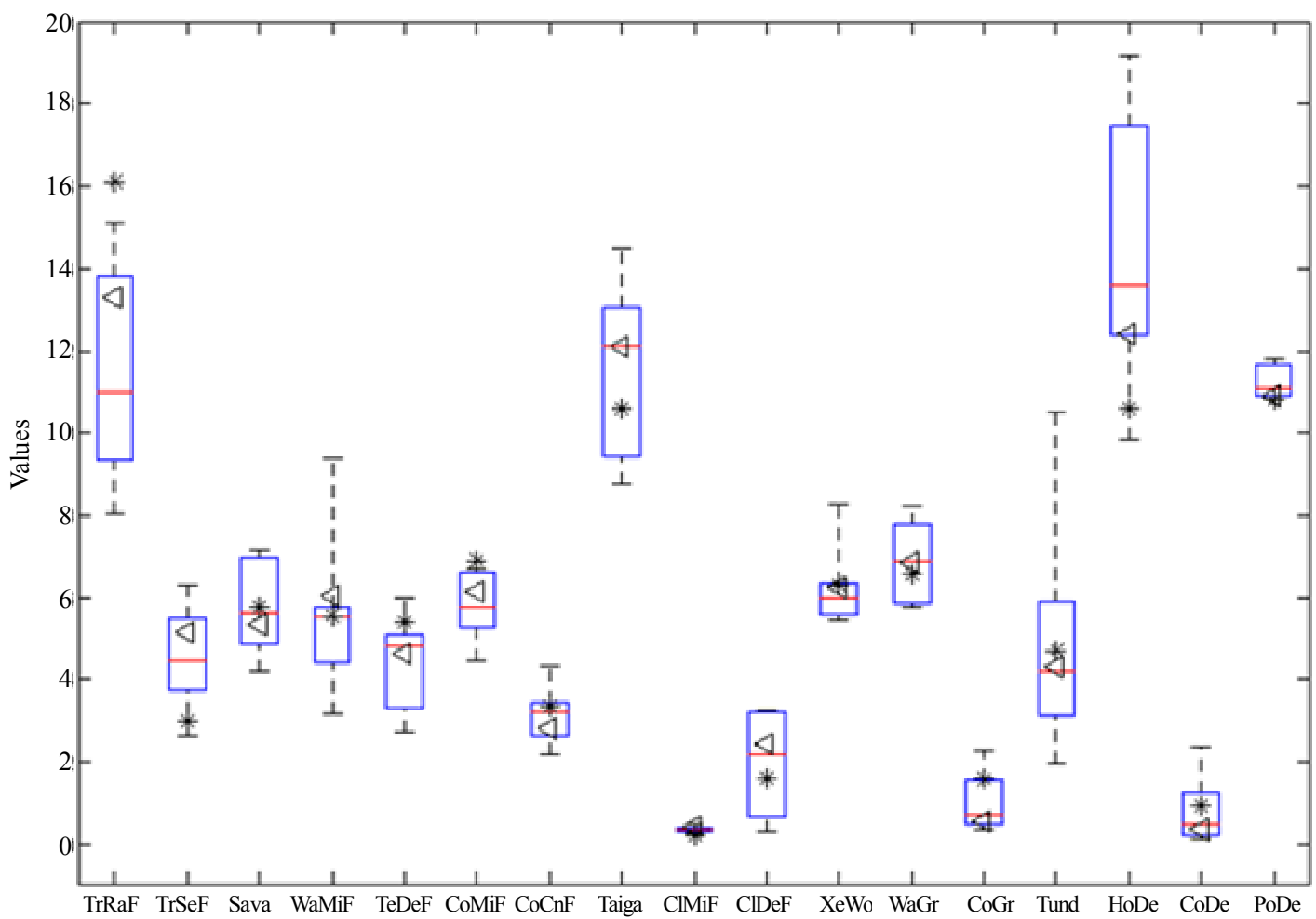

Figure 3. Global mean biome distribution, calculated from the "observed" climate (cf. Figure 5(a)) and from simulated climate by all models. Boxes: $25 \%-75 \%$, whiskers: min and max, horizontal line: mean of all simulated biome changes, triangle: biome change calculated from ensemble mean climate change. Asterisks: "observed" biome distribution. 


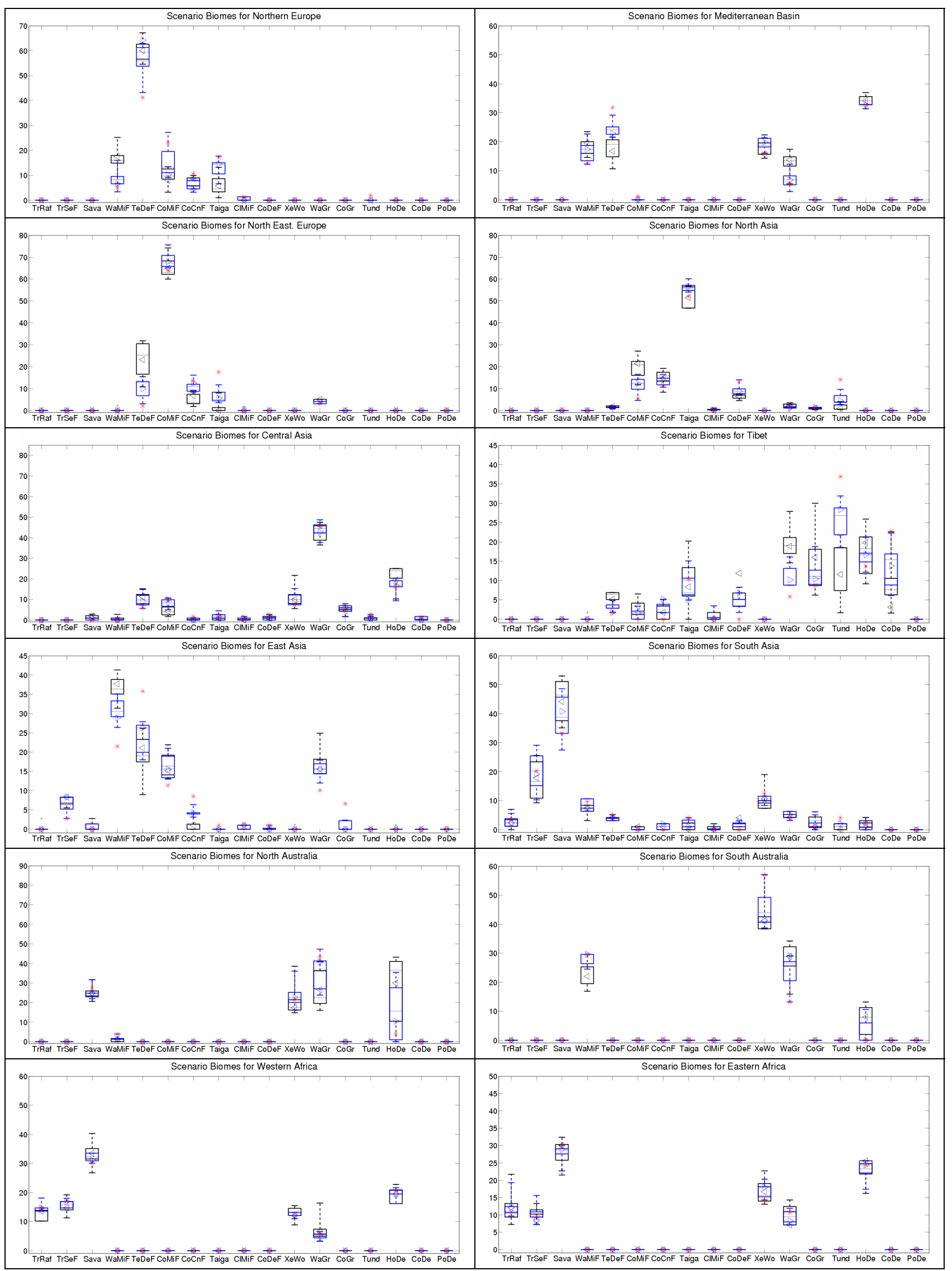




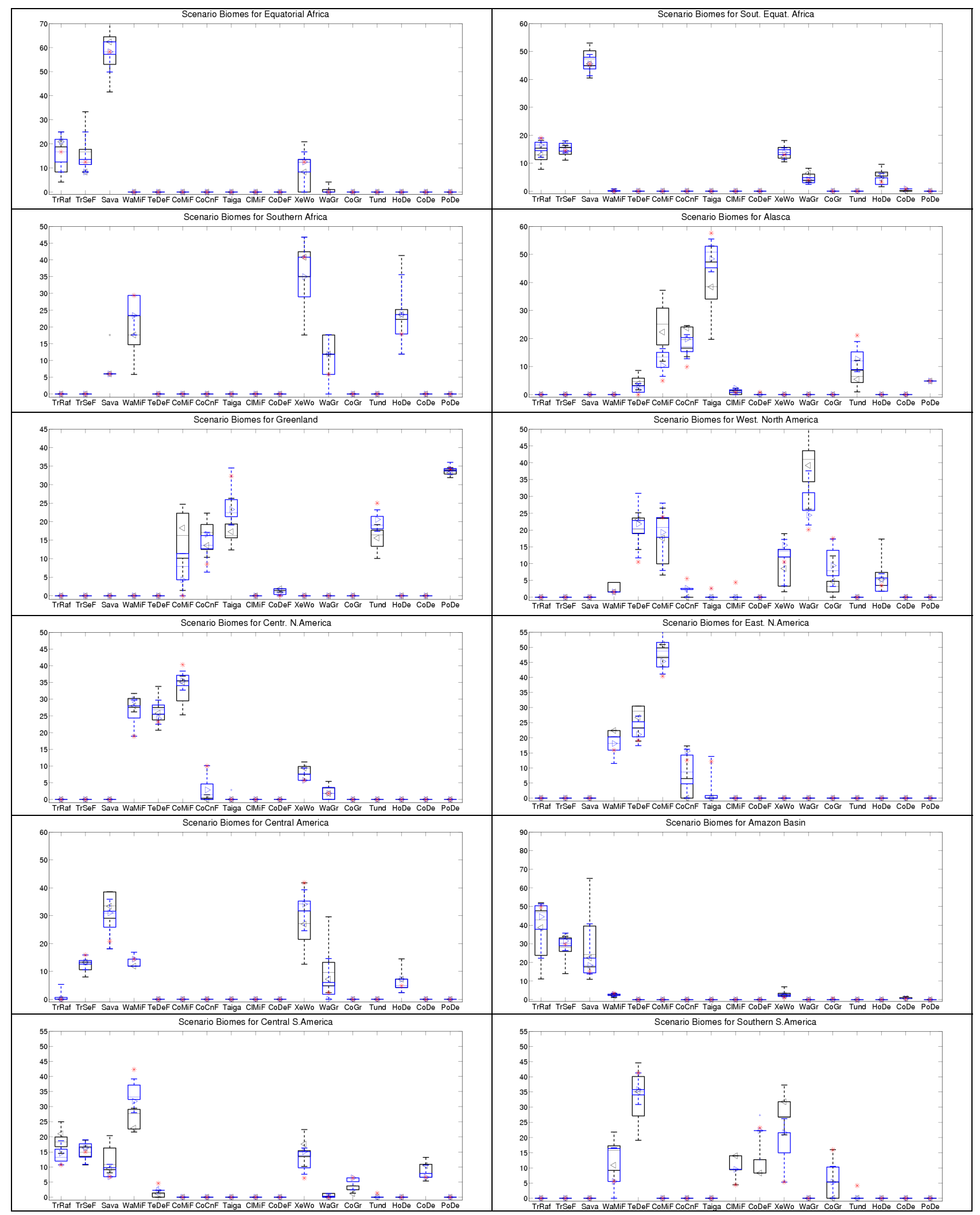

Figure 4. 2080-2099 biome distribution for Giorgi-regions for scenarios A1B (black) and E1 (blue), Boxes: 25\% - 75\%, whiskers: min and max, horizontal line: mean of all simulated biome changes, triangle: biome change calculated from ensemble mean climate change, cross: outlier (deviation $>2 \sigma$ ). Red asterisks: "observed" biome distribution. Note the differing y-axis for different regions. 
subtropics an increase in drier climate biomes is projected in both scenarios. In Australia, consistent with the precipitation decrease [8], hot desert replaces warm grassland and xerophytic woods. This projected desertification is stronger in the A1B scenario than in the E1 scenario, even though the spread between the models is large $(>30 \%$ for hot desert in North Australia, NAU, in A1B). In Southern Africa (SAF) the area of warm mixed forests decreases in all models in both scenarios, but is replaced by warm grassland in some models and by hot deserts in others.

In the mid-latitudes biomes with a higher cold tolerance are replaced by biomes that require longer growing periods (Figure 4). In both scenarios most models show an increased extent of warm mixed forests (ENA, EAS, CNA, NEU and SSA) and in some regions temperate deciduous forests (CNA, WNA, NEU) by the end of the $21^{\text {st }}$ century. On the other hand, the extent of taiga (ENA, WNA, NEU) and cold coniferous forests (ENA, CNA, EAS) decreases according to most models. In Northern Europe (NEU) tundra disappears in all models by the end of the $21^{\text {st }}$ century. In (WNA) taiga and cool mixed forest disappear in both scenarios. In addition, cold coniferous forests disappear in the SRES A1B scenario, while in the E1 scenario some remain. Considerably lower changes in biomes in E1 compared to $\mathrm{A} 1 \mathrm{~B}$ are evident in the mid-latitudes. For example, in WNA, the first quartile of the simulated fraction of warm and cold grasslands is higher than the third quartile in the E1 scenario under the A1B scenario. This is consistent with the stronger summer drying in this area in the SRES A1B scenario.

As a result of temperature changes there is amplification of biome changes in polar and subpolar latitudes (Figure 4). Taiga and tundra are replaced by temperate deciduous forests, cold mixed forests and cold coniferous forests (NEE, NAS, GRL, ALA). Although the main features of biome changes in the two scenarios are similar across these latitudes, the strength of biome changes differs significantly.

In Tibet (TIB) the area of tundra and cold deserts decreases in both scenarios, while the area of cold deciduous forest and warm grassland increases. Despite of the large inter-model spread the $25^{\text {th }}$ and the $75^{\text {th }}$ percentiles of changes in tundra and warm grassland for the two scenarios do not overlap.

\section{Summary and Conclusions}

We have assessed the difference in resulting biome shifts for different regions of the world when following an ambitious mitigation scenario (E1) as compared with a baseline scenario (SRES A1B) using multi-model results from 10 state-of-the-art coupled atmosphere-ocean general circulation models (GCMs).
Resulting biome changes in the mid-latitudes and sub-polar regions are larger than those in the tropics and subtropics. In the mid-latitudes and sub-polar regions, biomes with less freezing resistance and a higher demand for growing degree days replace the current vegetation consistent with previous studies (e.g. [19]). In the subtropics and tropics biome changes reflect precipitation decrease over land confirming previous results (e.g. [13, 25]). Considerable uncertainty in the likelihood of dieback of the Amazonian rainforest due to climate change and vegetation feedbacks remains [26]. The particularly strong potential vegetation change for the Amazonas region in HadCM3C and HadGEM2-AO compared to the other analyzed GCMs is consistent with the simulated strong forcing response in these regions for precipitation and cloud cover as shown by [8].

In 13 of the 26 regions, namely NEU, MED, NEE, NAS, CAS, TIB, EAS, SAU, ALA, GRL, WNA, CSA and SSA, differences at least for some of the projected biomes changes are much smaller in the E1 scenario than in the A1B scenarios. Thus, in these regions strong mitigation actions could significantly reduce changes in growing conditions when compared with a non-mitigation scenario. On the other hand, even under the E1 scenario, considerable changes in the biome distribution are projected in some regions, particularly in biomes tundra, taiga and cold grassland (e.g. Regions NAS, TIB, EAS, ALA, GRL) but also in the form of shifts from Cold Mixed Forest to Temperate Deciduous Forest and from this to Warm Mixed Forest (e.g. NEU, EAS, CNA, CSA). These regions seem to be particularly sensitive to climate change impacts on growing conditions and might suffer adverse impacts even under strong climate change mitigation action, indicating the need for adaptation measures.

While the vegetation patterns presented here are not the existing vegetation in large parts of the world but the potential vegetation calculated from climatic conditions, they nevertheless provide important insights into growing conditions in different parts of the world under present day conditions and under the two future scenarios considered. Instead of using the most sophisticated available biome models, we use a simple model to account for the coarse resolution of our data and to restrict the analysis to a limited number of biomes and dominant changes between them. Furthermore we did not use the vegetation patterns simulated by the embedded terrestrial carbon cycle components of some of the models but calculated biomes forced by all the models' physical output. The advantage is that we can provide a multi model analysis of 10 state-of-the-art global climate models and the response of terrestrial biomes to the climate change signals simulated by them for the two scenarios. Thus, we provide a consistent overview of potential vegetation 
response to an ambitious mitigation scenario (E1) compared to a baseline scenario (A1B). Further research should focus on the regions with the largest sensitivity to climate change with respect to growing conditions. In these regions, both natural vegetation and anthropogenic land-use should be reviewed as to their resilience under projected climate change for different forcing scenarios.

\section{Acknowledgements}

The ENSEMBLES model-outputs used in this work were produced with the partial funding of the EU FP6 Integrated Project ENSEMBLES (Contract number 505539), whose support is gratefully acknowledged.

\section{REFERENCES}

[1] R. H. Moss, et al., "The Next Generation of Scenarios for Climate Change Research and Assessment," Nature, Vol. 463, 2010, pp. 747-756. doi:10.1038/nature08823

[2] P. van der Linden and J. F. B. Mitchell, "ENSEMBLES: Climate Change and Its Impacts: Summary of Research and Results from the ENSEMBLES Project," Met Office Hadley Centre, 2009, 160 p.

[3] J. A. Lowe, C. D. Hewitt, D. P. van Vuuren, T. C. Johns, E. Stehfest, J.-F. Royer and P. J. van der Linden, "New Study for Climate Modeling, Analyses, and Scenarios," Eos, Transactions American Geophysical Union, Vol. 90, No. 21, 2009, pp. 181-182. doi:10.1029/2009EO210001

[4] T. C. Johns, J.-F. Royer, I. Höschel, H. Huebener, E. Roeckner, E., Manzini, W. May, J.-L. Dufresne, O. H. Otterå, D. P. van Vuuren, D. Salas y Melia, M. Giorgetta, S. Denvil, S. Yang, P. G. Fogli, J. Körper and C. D. Hewitt, "Climate Change under Aggressive Mitigation: The ENSEMBLES Multi-Model Experiment," Climate Dynamics, Vol. 37, No. 9-10, 2011, pp. 1975-2003. doi:10.1007/s00382-011-1005-5

[5] D. G. Streets, et al., "Two-Decadal Aerosol Trends as a Likely Explanation of the Global Dimming/Brightening Transition," Geophysical Research Letters, Vol. 33, No. 15, 2006, p. L15806. doi:10.1029/2006GL026471

[6] M. I. Mischchenko, et al., "Long-Term Satellite Record Reveals Likely Recent Aerosol Trend," Science, Vol. 315, No. 5851, 2007, p. 1543. doi:10.1126/science.1136709

[7] G. A. Meehl, T. F. Stocker, et al., "Global Climate Projections," In: S. Solomon, et al., Eds., Climate Change 2007: The Physical Science Basis, Cambridge University Press, Cambridge, New York, 2007, pp. 747-846.

[8] H. Huebener, M. G. Sanderson, I. Höschel, J. Körper, T. C. Johns, J.-F. Royer, E. Roeckner, E. Manzini, J.-L. Dufresne, O. H. Otterå, J. Tjiputra, D. S. Y Melia, M. Giorgetta, S. Denvil and P. G. Fogli, "Regional Hydrological Cycle Changes in Response to an Ambitious Mitigation Scenario," Climatic Change, 2013. doi:10.1007/s10584-013-0829-x

[9] J. Körper, I. Höschel, J. A. Lowe, C. D. Hewitt, D. Salas y Melia, E. Roeckner, H. Huebener, J.-F. Royer, J.-L.
Dufresne, A. Pardaens, M. A. Giorgetta, M. G. Sanderson, O. H. Otterå, J. Tjiputra and S. Denvil, "The Effects of Aggressive Mitigation on Steric Sea Level Rise and Sea Ice Changes," Climate Dynamics, Vol. 40, No. 3-4, 2013, pp. 531-550. doi:10.1007/s00382-012-1612-9

[10] A. Fischlin, G. F. Midgley, J. T. Price, R. Leemans, B. Gopal, C. Turley, M. D. A. Rounsevell, O. P. Dube, J. Tarazona and A. A. Velichko, "Ecosystems, Their Properties, Goods, and Services," In: M. L. Parry, O. F. Canziani, J. P. Palutikof, P. J. van der Linden and C. E. Hanson, Eds., Climate Change 2007: Impacts, Adaptation and Vulnerability, Cambridge University Press, Cambridge, 2007, pp. 211-272.

[11] O. E. Sala, F. S. Chapin, J. J. Armesto, E. Berlow, J. Bloomfield, R. Dirzo, E. Huber-Sanwald, L. F. Huenneke, R. B. Jackson, A. Kinzig, R. Leemans, D. M. Lodge, H. A. Mooney, M. Oesterheld, A. L. Poff, M. T. Sykes, B. H. Walker, M. Walker and D. H. Wall, "Global Biodiversity Scenarios for the Year 2100," Science, Vol. 287, No. 5459, 2000, pp. 1770-1774.

[12] A. D. Hansen, R. P. Neilson, V. H. Dale, C. H. Flather, L. R. Iverson, D. J. Currie, S. Shaver, R. Cook and P. J. Bartlein, "Global Change in Forests: Responses of Species, Communities and Biomes," BioScience, Vol. 51, No. 9, 2001, pp. 765-779. doi:10.1641/0006-3568(2001)051[0765:GCIFRO]2.0.CO ;2

[13] S. Sitch, C. Huntingford, N. Gedney, P. E. Levy, M. Lomas, S. L. Piao, R. Betts, P. Ciais, P. Cox, P. Friedlingstein, C. D. Jones, I. C. Prentice and F. I. Woodward, "Evaluation of the Terrestrial Carbon Cycle, Future Plant Geography and Climate-Carbon Cycle Feedbacks Using Five Dynamic Global Vegetation Models (DGVMs)," Global Change Biology, Vol. 14, No. 9, 2008, pp. 20152039. doi:10.1111/j.1365-2486.2008.01626.x

[14] M. Kirschbaum and A. Fischlin, "Climate Change Impacts on Forests," In: R. Watson, M. C. Zinyowera and R. H. Moss, Eds., Climate Change 1995: Impacts; Adaptations and Mitigation of Climate Change. Scientific-Technical Analysis, Cambridge University Press, Cambridge, 1996, pp. 95-129.

[15] I. C. Prentice, W. Cramer, S. P. Harrison, R. Leemans, R. A. Monserud and M. A. Solomon, "A Global Biome Model Based on Plant Physiology and Dominance, Soil Properties and Climate" Journal of Biogeography, Vol. 19, No. 2, 1992, pp. 117-134. doi:10.2307/2845499

[16] W. May, "Climatic Changes Associated with a Global ' $2{ }^{\circ} \mathrm{C}$-Stabilization' Scenario Simulated by the ECHAM5/ MPI-OM Coupled Climate Model," Climate Dynamics, Vol. 31, No. 2-3, 2008, pp. 283-313. doi:10.1007/s00382-007-0352-8

[17] J. H. Christensen, B. Hewitson, et al., "Regional Climate Projections,” In: S. Solomon, et al., Eds., Climate Change 2007: The Physical Science Basis, Cambridge University Press, Cambridge, New York, 2007, Chapter 11.

[18] F. Giorgi and X. Bi, "Updated Regional Precipitation and Temperature Changes for the 21st Century from Ensembles of Recent AOGCM Simulations," Geophysical Research Letters, Vol. 32, No. 21, 2005, p. L21715. doi:10.1029/2005GL024288 
[19] J. O. Kaplan, et al., "Climate Change and Arctic Ecosystems: 2. Modeling, Paleodata-Model Comparisons, and Future Projections," Journal of Geophysical Research: Atmospheres, Vol. 108, No. D19, 2003, p. 8171. doi:10.1029/2002JD002559

[20] T. D. Mitchell and P. D. Jones, "An Improved Method of Constructing a Database of Monthly Climate Observations and Associated High-Resolution Grids," Journal of Geophysical Research: Atmospheres, Vol. 25, No. 6, 2005, pp. 693-712. doi:10.1002/joc.1181

[21] G. J. Huffman, R. F. Adler, M. Morrissey, D. T. Bolvin, S. Curtis, R. Joyce, B. McGavock and J. Susskind, "Global Precipitation at One-Degree Daily Resolution from MultiSatellite Observations," Journal of Hydrometeorology, Vol. 2, No. 1, 2001, pp. 36-50. doi:10.1175/1525-7541(2001)002<0036:GPAODD >2.0.C $\underline{\mathrm{O} ; 2}$

[22] M. de Castro, C. Gallardo, K. Jylha and K. Tuomenvirta, "The Use of a Climate-Type Classification for Assessing Climate Change Effects in Europe from Ensemble of Nine Regional Climate Models," Climatic Change, Vol.
81 , No. 1 , 2007, pp. 329-342. doi:10.1007/s10584-006-9224-1

[23] F. Hanf, J. Körper, T. Spangehl and U. Cubasch, "Shifts of Climate Zones in Multi-Model Climate Change Experiments Using the Koppen Climate Classification," Meteorologische Zeitschrift, Vol. 21, No. 2, 2012, pp. 111-123. doi:10.1127/0941-2948/2012/0344

[24] R. A. Monserud and R. Leemans, "Comparing Global Vegetation Maps with the Kappa Statistic," Ecological Modelling, Vol. 62, No. 4, 1992, pp. 275-293. doi:10.1016/0304-3800(92)90003-W

[25] C. A. Alo and G. Wang, "Potential Future Changes of the Terrestrial Ecosystem Based on Climate Projections by Eight General Circulation Models," Journal of Geophysical Research, Vol. 113, No. G1, 2008, p. G01004. doi:10.1029/2007JG000528

[26] Y. Malhi, et al., "Exploring the Likelihood and Mechanism of a Climate-Change Induced Dieback of the Amazon Rainforest," Proceedings of the National Academy of Sciences, Vol. 106, No. 49, 2009, pp. 20610-20615. doi:10.1073/pnas.0804619106 